\title{
Nitric Oxide Alters the Pattern of Auxin Maxima and PIN-FORMED1 During Shoot Development
}

\author{
Inmaculada Sánchez-Vicente, Tamara Lechón, María Fernández-Marcos, Luis Sanz and \\ Oscar Lorenzo*
}

Departamento de Botánica y Fisiología Vegetal, Instituto Hispano-Luso de Investigaciones Agrarias (CIALE), Facultad de Biología, Universidad de Salamanca, Salamanca, Spain

OPEN ACCESS

Edited by:

Rujin Chen,

Lanzhou University, China

Reviewed by:

Steffen Vanneste,

Ghent University, Belgium

José López-Bucio,

Universidad Michoacana de San

Nicolás de Hidalgo, Mexico

${ }^{*}$ Correspondence:

Oscar Lorenzo

oslo@usal.es

Specialty section:

This article was submitted to

Plant Physiology,

a section of the journal

Frontiers in Plant Science

Received: 18 November 2020

Accepted: 01 April 2021

Published: 26 April 2021

Citation:

Sánchez-Vicente I, Lechón T,

Fernández-Marcos M, Sanz L and

Lorenzo O (2021) Nitric Oxide Alters

the Pattern of Auxin Maxima and

PIN-FORMED1 During Shoot

Development.

Front. Plant Sci. 12:630792.

doi: 10.3389/fpls.2021.630792
Hormone patterns tailor cell fate decisions during plant organ formation. Among them, auxins and cytokinins are critical phytohormones during early development. Nitric oxide (NO) modulates root architecture by the control of auxin spatial patterns. However, NO involvement during the coordination of shoot organogenesis remains unclear. Here, we explore the effect of $\mathrm{NO}$ during shoot development by using a phenotypic, cellular, and genetic analysis in Arabidopsis thaliana and get new insights into the characterization of NO-mediated leaf-related phenotypes. NO homeostasis mutants are impaired in several shoot architectural parameters, including phyllotactic patterns, inflorescence stem elongation, silique production, leaf number, and margin. Auxin distribution is a key feature for tissue differentiation and need to be controlled at different levels (i.e., synthesis, transport, and degradation mechanisms). The phenotypes resulting from the introduction of the cue 1 mutation in the axr1 auxin resistant and pin1 backgrounds exacerbate the relationship between $\mathrm{NO}$ and auxins. Using the auxin reporter DR5:GUS, we observed an increase in auxin maxima under NO-deficient mutant backgrounds and $\mathrm{NO}$ scavenging, pointing to NO-ASSOCIATED 1 (NOA1) as the main player related to NO production in this process. Furthermore, polar auxin transport is mainly regulated by PIN-FORMED 1 (PIN1), which controls the flow along leaf margin and venations. Analysis of PIN1 protein levels shows that NO controls its accumulation during leaf development, impacting the auxin mediated mechanism of leaf building. With these findings, we also provide evidence for the NO opposite effects to determine root and shoot architecture, in terms of PIN1 accumulation under $\mathrm{NO}$ overproduction.

Keywords: auxin response, auxin transport, leaf morphology, nitric oxide homeostasis mutants, PIN-FORMED 1

\section{INTRODUCTION}

Leaf initiation from the shoot apical meristem (SAM), and later development are controlled by networks composed by plant hormones and transcriptional factors, which determine organ form and size. Leaf shape and size change between different species and around an individual plant. Although some variation exists depending on environmental circumstances and internal conditions, main signaling mechanisms surrounding these processes are influenced by spatial patterns based on auxin gradients (Avsian-Kretchmer et al., 2002; Heisler et al., 2005; 
Cheng et al., 2007; Marcos and Berleth, 2014). Specific points of auxin maxima are described previously to leaf initiation, involving changes in the polar localization of efflux carriers [i.e., PIN-FORMED (PIN1) proteins]. PIN transporters modulate this auxin flow in a highly controlled manner in order to organize cell and organ growth (Reinhardt et al., 2000, 2003; Benková et al., 2003; Qi et al., 2014).

During the regulation of physiological and stress processes, the gasotransmitter nitric oxide (NO) usually interacts with plant hormones and other endogenous molecules, affecting their biosynthesis, catabolism, transport, perception, and signal transduction (reviewed in Freschi, 2013; Sanz et al., 2015). Even though NO synthesis in plants is still partially unresolved, the best characterized mechanisms involve the reduction of nitrite by NITRATE REDUCTASES 1 (NIA1) and 2 (NIA2) and the oxidation in an arginine-dependent pathway by NO-ASSOCIATED 1 (NOA1), similar to the animal NO synthase (NOS) activity (reviewed in Astier et al., 2018). There is plenty of evidence that $\mathrm{NO}$ acts downstream of auxin (just in A. thaliana, Lombardo et al., 2006; Flores et al., 2008; Kolbert et al., 2008; Kolbert and Erdei, 2008; Chen et al., 2010; Wang et al., 2010; Schlicht et al., 2013; Cao et al., 2017; Fattorini et al., 2017; Moro et al., 2017; Sun et al., 2017; Liu et al., 2018), but several reports have shown that mutants which overproduce $\mathrm{NO}$ or the addition of exogenous $\mathrm{NO}$ also increase auxin levels (Xu et al., 2010; Chen et al., 2013; Elhiti et al., 2013; Manoli et al., 2015; Wen et al., 2016). However, the role of NO in auxin accumulation seems to be indirect. The use of NO donors in Medicago truncatula seedlings under cadmium stress improves stress tolerance by reducing indoleacetic acid (IAA) oxidase-driven auxin degradation, thus maintaining auxin equilibrium (Xu et al., 2010). Furthermore, knocking out phytoglobins (PGBs), which increase endogenous NO levels, inhibits auxin metabolism, resulting in a drastic modification of embryogenesis and root development (Elhiti et al., 2013).

Since NO had been described to act downstream of auxin, especially during root hair (Lombardo et al., 2006) and lateral root formation (Wang et al., 2010; Cao et al., 2017), Terrile et al. (2012) demonstrated that it might do so through promotion of auxin signaling via $S$-nitrosation of TIR1, which would enhance the interaction between $\mathrm{SCF}^{\mathrm{TTR} 1}$ and the Aux/IAAs, facilitating their degradation. However, previous reports had shown that, even though pharmacological NO donors increased lateral root formation and inhibited primary root development, they did not increase auxin response, since they could not elicit auxinresponsive promoters DR5::uidA and BA3::uidA (Méndez-Bravo et al., 2010; Petö et al., 2011). This was later confirmed using NO-overproducer mutants (Fernández-Marcos et al., 2011) and since then, several independent researchers have shown that AXR3/IAA17, one of the Aux/IAA transcriptional repressors, is stabilized by NO (Shi et al., 2015, 2017; Yuan and Huang, 2016). In addition, NO represses TIR1 transcription (Vitor et al., 2013), so it seems that the interaction between $\mathrm{NO}$ and auxin is mostly antagonistic. The observed reduction in auxin response caused by high levels of $\mathrm{NO}$ might be explained by a reduction in polar auxin transport (Fernández-Marcos et al., 2011), and NO homeostasis mutants present alterations in auxin transport
(Fernández-Marcos et al., 2011; Sanz et al., 2014; Shi et al., 2015), an effect that can be replicated using a pharmacological approach (Adamakis et al., 2014; Sanz et al., 2014; Yuan and Huang, 2016; Sun et al., 2017; Liu et al., 2018). Furthermore, it has been shown that GSNO affects the polar distribution of PIN2 in roots during gravitropism (Ni et al., 2017; París et al., 2018).

To extend our understanding of the effect of NO during shoot organization and leaf determination, we have studied the phenotype of NO homeostasis mutants, highlighting an altered leaf phenotype, including size and number of leaves and structural characteristics like the number of serrations. We also detected defects related to shoot architectural parameters, including phyllotactic patterns, inflorescence stem elongation, and silique production. In order to deepen on the NO and auxin crosstalk, we studied the weakened phenotypes resulting from the introduction of cuel mutation in auxin resistant 1 (axr1) background (a mutant with impaired auxin signaling since AXR1 is required for $\mathrm{SCF}^{\mathrm{TTR} / \mathrm{AFB}}$ functionality and perception of the hormone), and in pin1 mutant (altered in auxin transport). Furthermore, NO-overproducing mutants and exogenous NO treatments decrease the expression of auxin response reporter DR5:GUS but promote the accumulation of PIN1 protein levels, coincident with an alteration of auxin transport. Accordingly, NO deficiency promotes an increase in the auxin maxima and a decrease in PIN1 accumulation at early developmental stages. Finally, we show that the main NO synthesis mechanism contributing to the regulation of leaf auxin maxima is related with the NOA1 pathway, since no dramatic DR5:GUS increase is observed in NR deficient mutants. These results confirm the relevance of $\mathrm{NO}$ in the distribution of auxin gradients along the leaf, mainly at early developmental stages.

\section{MATERIALS AND METHODS}

\section{Plant Materials and Treatments}

Arabidopsis thaliana ecotype Columbia-0 (Col-0) is the genetic background for all wild type plants used in this work, except cue1-1 which is in the Bensheim (Be-0) ecotype background. Seed stocks pPIN1:PIN1-GFP, DR5:GUS, and cue1/nox1 were obtained from ABRC. Genetic crosses were performed using the cuel/nox1 and the noal-1 mutant as donor in all the cases and the corresponding acceptor lines axr1-3, pin1, pPIN1:PIN1-GFP, and DR5:GUS, as described in FernándezMarcos et al. (2011) and Sanz et al. (2014). axr1-3, axr6-3, and pin 1 mutants were a kind gift from Dr. James A.H. Murray (Cardiff University, Cardiff, United Kingdom), nia1nia2noa1-2 mutant was a kind gift from Dr. José León (IBMCP-CSIC, Valencia, Spain), and venosa (ven) and dov1 mutants were kindly provided by Dr. José Luis Micol (UMH, Elche, Spain). axr1-3 mutant was generated by mutagenizing a Col- 0 population with EMS (Lincoln et al., 1990), and it harbors a point mutation that changes a cysteine from the active site into an alanine, rendering the protein inactive. Arabidopsis plants used throughout this work were grown routinely in a growth chamber under $50-60 \%$ humidity, a temperature of $22^{\circ} \mathrm{C}$, and with a $16 \mathrm{~h}$ 
light/8 $\mathrm{h}$ dark photoperiod at $80-100 \mu \mathrm{E} \mathrm{m} \mathrm{m}^{-2} \mathrm{~s}^{-1}$ in pots containing a 1:3 vermiculite:soil mixture.

For in vitro culture, Arabidopsis seeds were surface-sterilized in $75 \%(\mathrm{v} / \mathrm{v})$ bleach solution (4-5\% sodium hypochlorite) and $0.01 \%(\mathrm{v} / \mathrm{v})$ Triton $\mathrm{X}-100$ for $5 \mathrm{~min}$ and washed three times in sterile water before sowing. Seeds were stratified for 3 days at $4^{\circ} \mathrm{C}$ and then grown on MS medium (Murashige and Skoog, 1962). Petri dishes containing solid medium composed of MS basal salts and $2 \%(\mathrm{w} / \mathrm{v})$ Gluc were solidified with $0.6 \%(\mathrm{w} / \mathrm{v})$ agar, and the $\mathrm{pH}$ was adjusted to 5.7 with $\mathrm{KOH}$ before autoclaving. Plates were sealed and incubated horizontally in a controlled environment growth chamber. For the different treatments, seeds were sown in MS vertical sealed plates and maintain for $7,10,15,21$, and 30 days, after which were changed to vertical plates supplemented with $300 \mu \mathrm{M} N O$ donor SNAP (S-Nitroso-N-acetyl-DL-penicillamine) or $1 \mathrm{mM}$ NO scavenger cPTIO [2-(4-carboxyphenyl)-4,4,5,5tetramethylimidazoline-1-oxyl-3-oxide] and incubated in the growth chamber during the different time periods.

\section{Measurement of Primary Root Length}

Plants were grown on plates containing a modified MS medium optimized for root growth, MSR [2.3 g/L MS (Duchefa Biochemie, Haarlem, The Netherlands), $15 \mathrm{~g} / \mathrm{L}$ agar], supplemented with glucose as indicated in Lechón et al. (2020). After full germination, root growth was captured by scanning plates with an Epson flatbed scanner and a resolution set to 600 ppi. Primary root length was assessed in at least three independent experiments, and individual seedlings were then measured using image analysis software Image J.

\section{Measurement of Phyllotactic Sequences}

Phyllotactic pattern was assessed on fully grown stems of 2-3 month-old plants. The top $5 \mathrm{~cm}$ of the stem were not assessed because elongation was incomplete. Divergence angle and inflorescence stem length were measured simultaneously using a custom-made device similar to the one used by Peaucelle et al. (2007). The divergence angle was measured between the insertion points of two successive floral pedicels and is therefore independent of the outgrowth direction of the pedicel. Phyllotactic orientation was determined by setting the direction giving the smallest divergence angle or closest to the expected $137.5^{\circ}$.

\section{GUS Staining}

GUS staining of DR5:GUS plants was performed using $50 \mathrm{mM}$ sodium phosphate buffer ( $\mathrm{pH} 7.0$ ) containing $0.5 \%(\mathrm{v} / \mathrm{v})$ Triton $\mathrm{X}-100,1 \mathrm{mM} \mathrm{K} / \mathrm{K}_{4} \mathrm{FeCN}, 0.05 \%$ (w/v) EDTA, and $1 \mathrm{mg} / \mathrm{ml}$ $\mathrm{X}$-Gluc (Duchefa). At least, 10 seedlings and plants per genotype were fixed $5 \mathrm{~min}$ in $90 \%(\mathrm{v} / \mathrm{v})$ acetone at $-20^{\circ} \mathrm{C}$ and after this at $37^{\circ} \mathrm{C}$ overnight. Tissue was cleared with $70 \%(\mathrm{v} / \mathrm{v})$ ethanol, and photographs were taken using a LEICA MZ 16 FA microscope coupled to a LEICA DFC 490 digital camera.

\section{Fluorescence Microscopy}

The fluorescent photographs of seedlings and leaves grown in vitro and expressing the $p$ PIN1:PIN1-GFP reporter gene under control of the PIN1 promoter for confocal microscopy were mounted in $100 \%$ glycerol and taken using a LEICA TCS SP2 confocal microscope. For GFP detection, the excitation source was an argon ion laser at $488 \mathrm{~nm}$ and detection filters between 500 and $550 \mathrm{~nm}$ and for the chlorophyll channel filters between 610 and $670 \mathrm{~nm}$.

\section{Detection of Endogenous NO}

Arabidopsis seedlings between 7- and 15-day-old were incubated in a $500 \mu \mathrm{l}$ solution containing $10 \mu \mathrm{M}$ of 4,5 -diamino-fluorescein diacetate (DAF-2DA, Sigma) in buffer $10 \mathrm{mM}$ Tris- $\mathrm{HCl}, \mathrm{pH}$ 7.4, during $2 \mathrm{~h}$ at $25^{\circ} \mathrm{C}$ in the dark. Seedlings were then washed three times for $15 \mathrm{~min}$ with fresh buffer $10 \mathrm{mM}$ Tris$\mathrm{HCl}$, pH 7.4. Finally, fluorescence emitted by DAF-2DA was detected on a LEICA MZ 16 FA microscope coupled to a LEICA DFC 490 digital camera and on a LEICA TCS SP2 confocal microscope by excitation at $495 \mathrm{~nm}$ and emission at $515 \mathrm{~nm}$. Quantification of fluorescence intensity was performed with Image s software. Four regions of interest (ROIs) were analyzed, corresponding to first and second leaves, shoot apical meristem (SAM), and petioles. The same area was selected in three biological replicates.

\section{Western Blotting}

Total protein extracts for western blot analysis were obtained from leaves of pPIN1:PIN1-GFP transgenic and corresponding mutant lines. Tissue was placed in a standard $1.5 \mathrm{ml}$ plastic microcentrifuge tube in the presence of extraction buffer $(5 \mathrm{mM}$ Tris- $\mathrm{HCl} \mathrm{pH}$ 6.8, 2 mM EGTA, 2 mM EDTA, 2\% SDS, and $1 \mathrm{x}$ proteases inhibitor mix, Roche) and was incubated on ice for $10 \mathrm{~min}$ followed by centrifugation for $10 \mathrm{~min}$ at $15800 \mathrm{~g}$ and $4^{\circ} \mathrm{C}$. Protein concentration was determined by the Bio-Rad Protein Assay (Bio-Rad) based on the Bradford method (Bradford, 1976). Total protein was loaded in SDS-acrylamide/bisacrylamide gel electrophoresis using Tris-glycine-SDS buffer. Proteins were electrophoretically transferred to Inmobilon ${ }^{\mathrm{TM}}$-P PVDF membrane (Millipore) using the Trans-Blot cell (Bio-Rad). Membranes were blocked in Tris buffered saline- $0.1 \%(\mathrm{v} / \mathrm{v})$ Tween 20 containing $5 \%(\mathrm{w} / \mathrm{v})$ blocking agent and probed with antibodies diluted in blocking buffer. Anti-GFP (Clontech), anti-Actin clone 10-B3 Purified Mouse Immunoglobulin (Sigma), ECL-Peroxidase labeled anti-mouse (Amersham), and anti-PIN1, kindly provided by Dr. Klaus Palme (University of Freiburg, Germany) antibodies were used in the western blot analyses. Detection was performed using ECL Advance Western Blotting Detection Kit (Amersham), and the chemiluminescence was detected using an Intelligent Dark-Box II, LAS-1000 scanning system (Fujifilm).

\section{RESULTS}

\section{NO Accumulates in Aerial Parts of Arabidopsis Seedlings}

The functions of NO are closely related to the accumulation sites in different tissues along the plant. The presence of NO has been well characterized in roots, around the 
elongation zone (Fernández-Marcos et al., 2011) and the stem cell niche (Sanz et al., 2014), but less information is available about the aerial parts. Previous research localizes NO synthesis in primary leaves and trichomes (Tun et al., 2006; Corpas et al., 2009). Using the DAF-2DA fluorescent dye, we observed a high NO accumulation around the meristematic zones and throughout the petioles of Col-0 seedlings (Figures 1A,B).

Additionally, NO was analyzed in the NO overaccumulator cue1/nox1, the NO deficient noa1-1 and venosa1 (ven1) mutants in seedlings between 7- and 15-day-old, using Col-0 as the wild type (Figures 1C-F). In the wild type fluorescence was mainly observed along the meristematic zones (Figure 1A), as previously described (Corpas et al., 2009). The greater NO accumulation corresponded to younger leaves of cue1/nox 1 as expected, while ven 1 and noa1-1 mutants showed a decrease along the aerial part (Figures $\mathbf{1 C}-\mathbf{F}$ ). These results revealed that NO production was specifically detected in the first leaves formed, where a physiological effect is presumed, since DAF-2DA has the advantage to detect $\mathrm{NO}$ accumulation very close to the production sites in cells.

\section{NO Homeostasis Mutants Present Abnormal Leaf Phenotypes}

Nitric oxide was described to be involved in the regulation of root development (Stöhr and Stremlau, 2006; Fernández-Marcos et al., 2011, 2012; Bai et al., 2014) and root stem cell maintenance (Sanz et al., 2014), but more information is needed to clarify its role during leaf morphology. A visual analysis of NO homeostasis mutants showed apparent defects associated with leaf morphology (Figures 2A-E) and structural characteristics, like the number of serrations (Figure 2F). The reduced number of true leaves in noa1-1 mutant showed a pale phenotype, with premature senescence in the oldest ones, as previously reported (Liu and Guo, 2013; Lv et al., 2019), and a low number of serrations. On the opposite, the NO overaccumulator cue1/nox1 exhibited a high number of smaller leaves, with a remarkable venosa phenotype, characterized by a different pigmentation between the green veins and the pale interveinal regions (also known as reticulate; Berná et al., 1999; Robles and Micol, 2001), and a greater number of serrations (Figure 2F).

A highly similar pale phenotype was also described as a consequence of mutations in the RETICULATA-RELATED gene
A
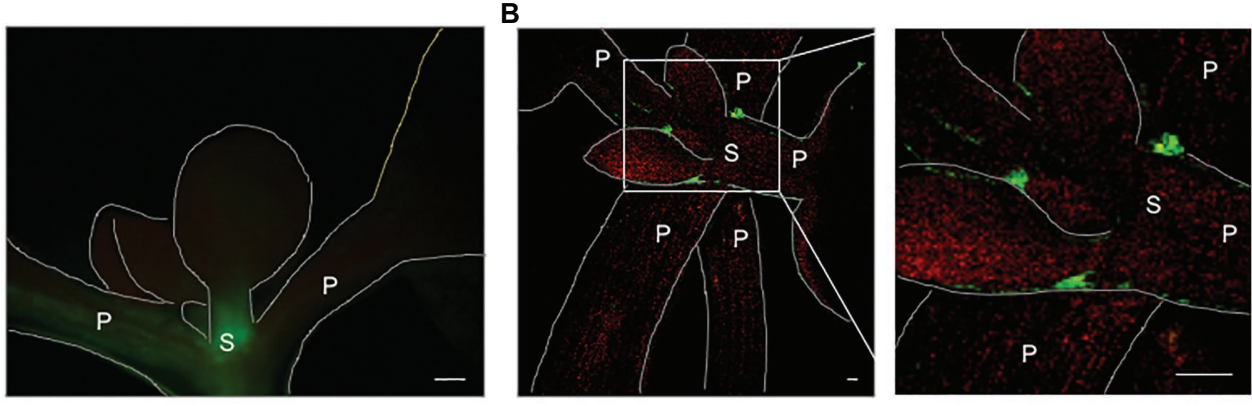

C
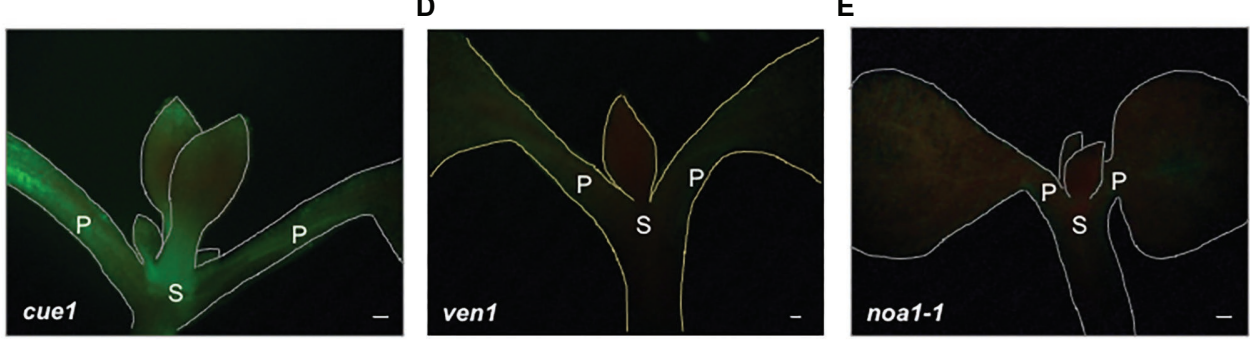

$\mathbf{F}$

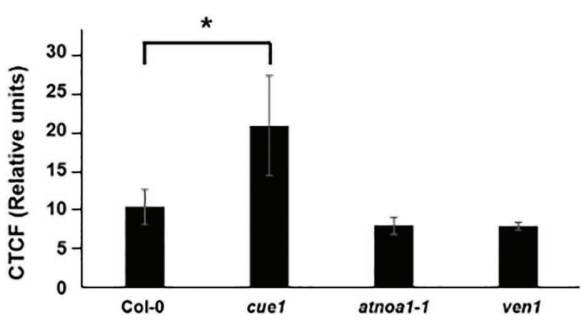

FIGURE 1 | Endogenous nitric oxide (NO) levels in Arabidopsis thaliana young leaves. Detection of endogenous NO production using 4,5-diamino-fluorescein diacetate (DAF-2DA) in Columbia-0 (Col-0; A,B), cue1/nox1 (C), ven1 (D), and NO-ASSOCIATED 1 (noa1-1; E) between 7- and 15-day-old seedling leaves observed with LEICA MZ 16 FA microscope coupled to with a LEICA DFC 490 digital camera (A,C-E) and with a Leica TCS SP2 confocal microscope (B). Quantitative data of NO-dependent DAF-2DA fluorescence leaf images. Values represent the mean \pm SE $(n=15)$. Asterisk indicates statistically significant difference compared to Col-0 ( $t$-test, ${ }^{*} p<0.05 ; \mathbf{F}$ ). Scale bars, $50 \mu \mathrm{m}$. P, petiole; S, stem. 

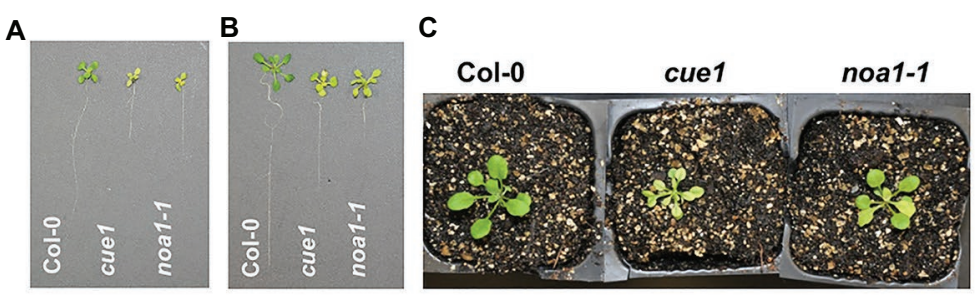

D

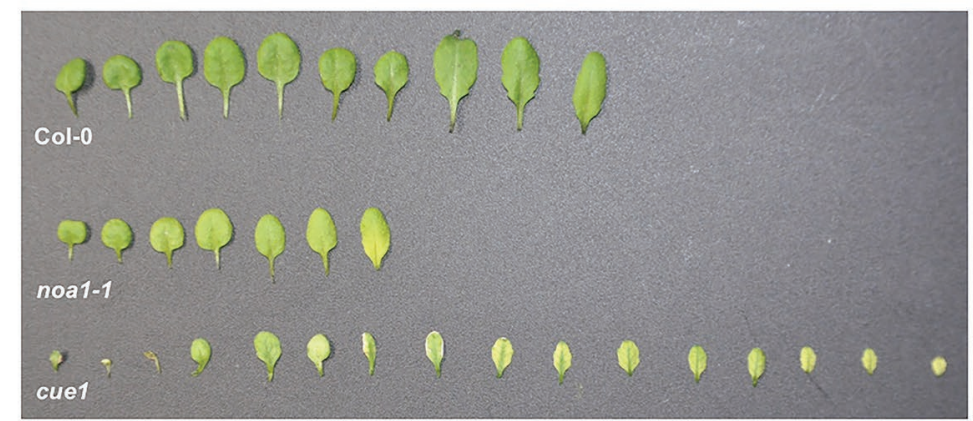

E

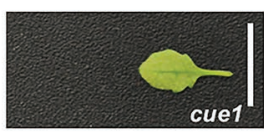

$\mathbf{F}$
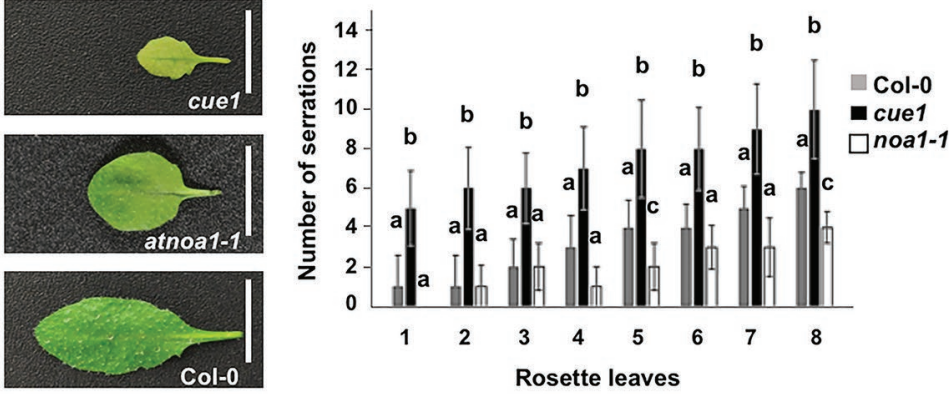

FIGURE 2 | Leaf phenotype of NO homeostasis mutants. Phenotype of 15-day-old seedlings (A), 21-day-old seedlings (B), 21-day-old plant rosettes (C), and 30-day-old plant leaves (D,E). Number of serrations in 30-day-old Arabidopsis leaves (F). The developmental number of the leaf is represented on the $X$-axis and cotyledons are not included. Values represent the mean $\pm S D(n=10)$. Col-0, the ecotype used as a control is compared with the NO overproducer cue1/nox 1 mutant and the NO deficient noa1-1.

family (González-Bayón et al., 2006; Pérez-Pérez et al., 2013) and $\underline{D}$ IFFERENTIAL DEVELOPMENT $\underline{\mathrm{O} F}$ VASCULAR ASSOCIATED CELLS 1 (DOV1) gene (Kinsman and Pyke, 1998; Rosar et al., 2012), independently of NO levels. Analyzing the root length variation in response to exogenous NO treatment, only cue1/nox 1 mutant underwent a significant reduction, as previously described (He et al., 2004; Fernández-Marcos et al., 2011), while we did not found any common correlation between the rest of venosa mutants, compared to the wild type (Supplementary Figure 1).

\section{NO Mutants Exhibit Additional Growth Defects During Aerial Part Development}

The phyllotaxis of a plant is defined as the stereotyped spatiotemporal pattern of organ initiation that results in the recognizable architecture of the plant. In the shoot apex, phyllotaxis is driven by the pattern of auxin distribution (Reinhardt et al., 2003). Given that NO homeostasis mutants present abnormal leaf phenotypes, we also studied organ phyllotaxis in cue1 and noal mutants to find out whether altered NO levels were translated into a phyllotactic phenotype (Figures 3A-D). For this reason, plants were grown for 2-3 months until their inflorescences were fully elongated, and the position of the plants was randomized to minimize environmental fluctuations. To assess the phyllotactic pattern, we measured the length of the primary inflorescence and the divergence angle between siliques. Arabidopsis thaliana has a spiral phyllotaxis, with a divergence angle of $137.5^{\circ}$ between successive organs, which is usually termed $\alpha$ or canonical angle (Galvan-Ampudia et al., 2016). However, a notable amount (83\%) of wild type plants also display organ permutations along the stem, that are measured as an angle sequence of $2 \alpha, 360-\alpha$, and $2 \alpha$ and give an "M motif" when a phyllotactic sequence is represented in a graph (Figure 3A). These permutations are the result of two organs initiated simultaneously in the SAM, and lead to a normal distribution or permutation depending on which organ is positioned above the other after internode elongation (Galvan-Ampudia et al., 2016). The phyllotactic sequences were quite similar for all three genotypes, 


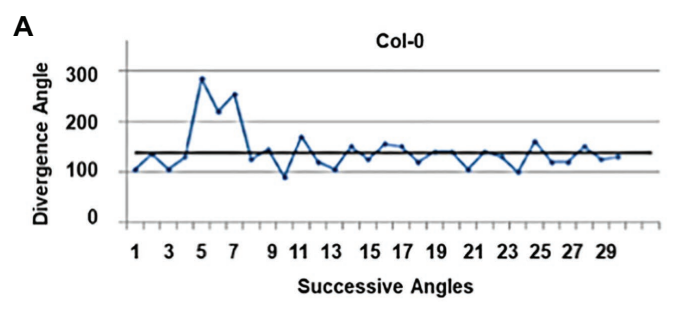

B
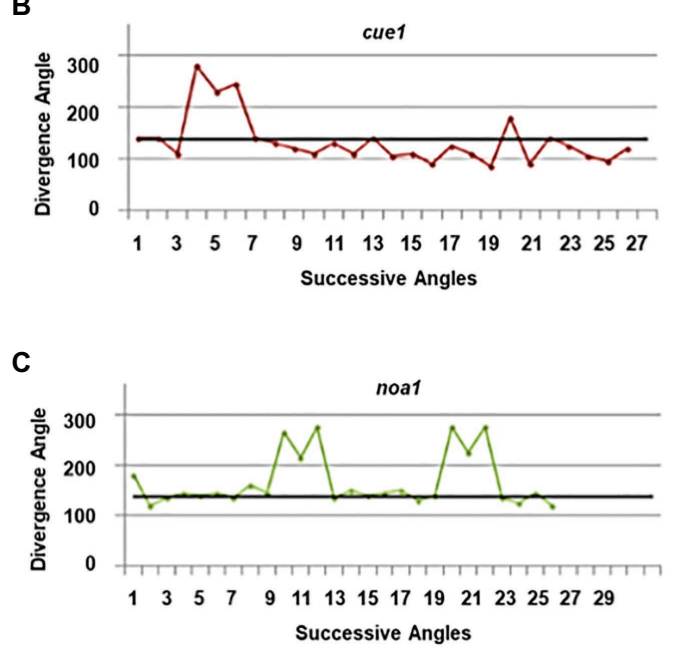
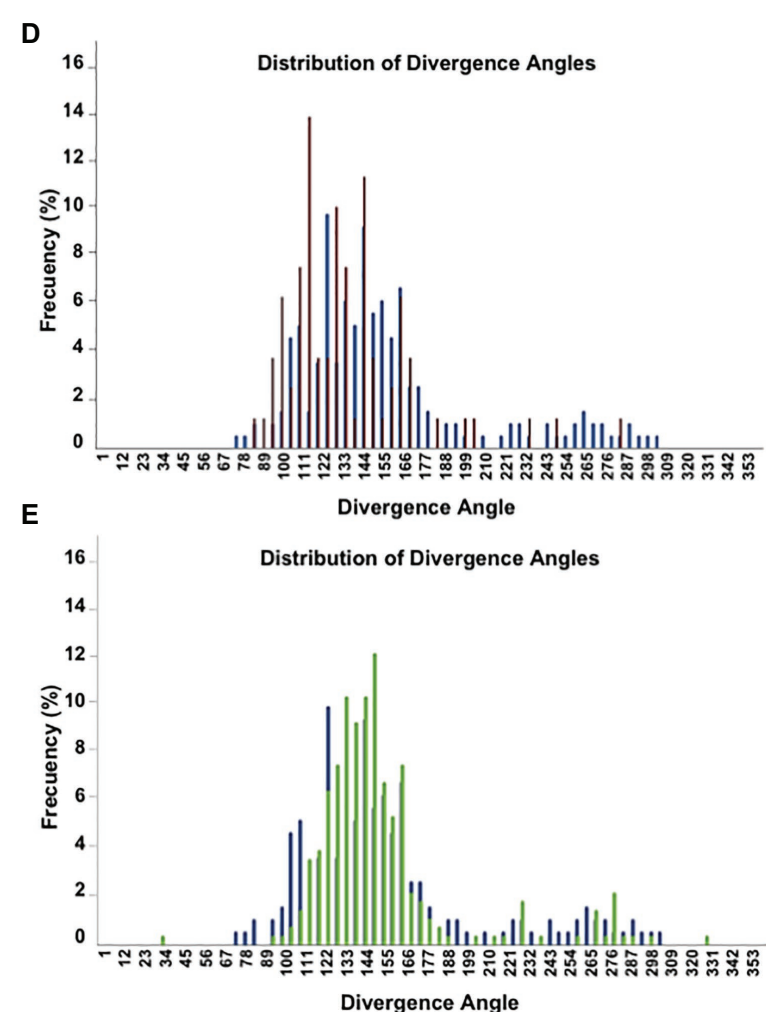

Divergence Angle

FIGURE 3 | Phyllotactic patterns of NO homeostasis mutants. Representative angle sequences of Col-0 (A), cue1 (B), and noa1 (C). The black lines represent the canonical angle sequence $\left(137.5^{\circ}\right.$ ) and colors in the graph correspond to Col-0 (blue), cue1 (red), and noa1 (green). Distribution of divergence angles for all analyzed phyllotactic sequences of Col-0 vs. cue1 (D) and Col-0 vs. noa1 (E). At least, 10 plants per genotype were analyzed.

as the relative angle between siliques and the position of their initiation relative to the center of the SAM were unaffected in cue1 and noa1 (Figures 3B,C). When we analyzed the frequency of divergence angles for all the phyllotactic sequences analyzed, most siliques were separated by angles that follow a normal distribution around the canonical angle (Figure 3D).

We also found that the number of permutations might be related to the endogenous NO content of the plant, since all noa1 plants presented permutations, $17 \%$ more than wild type plants. On the other hand, only $67 \%$ of cue1 plants had permutated siliques (Supplementary Table 1). The number of successive permutations, that is, of more than two siliques involved in successive permutations, was higher for noal than for Col-0 and, especially, cue1 plants. However, the permutation frequency for both mutants (one and three permutations per plant for cue1 and noal, respectively) is within the usual range of permutations in Col-0 plants (Besnard et al., 2014).

In addition to phyllotactic pattern analysis, we compared the length of the primary inflorescences of Col-0, cue1, and noa1. While the inflorescence of cue 1 is indeed $61 \%$ shorter than that of Col-0, both mutants have smaller inflorescences, as the inflorescence of noal is also $26 \%$ shorter. In the same way, both mutants have a higher silique production rate than wild type plants, as cue 1 has $2.92 \pm 0.19$ siliques $/ \mathrm{cm}$ of inflorescence, $48 \%$ more than Col-0, which only has $1.53 \pm 0.12$ siliques/cm, and noal has $2.36 \pm 0.12$ siliques/cm, 35\% more siliques than the wild type. However, the number of siliques per plant is quite different among the genotypes, as noal has $13 \%$ more siliques per plant compared to the wild type, and cue 1 has $24 \%$ less siliques per plant. Therefore, the increase in silique production seems to be a function of the decrease in inflorescence length and not a decrease in the rate of organ production, the plastochron, which, according to this data, seems to be unaltered in both NO homeostasis mutants (Supplementary Table 1). Recently, Ware et al. (2020) have proposed a framework to explain the arrest of Arabidopsis inflorescence as a local process driven by auxin export from fruit proximal to the inflorescence apex.

\section{Auxin Transport and Responses are Altered in cue1}

In Fernández Marcos et al. (2011), we showed that high levels of NO reduce the acropetal auxin transport. Furthermore, we observed certain similarities between the phenotypes of the cue 1 and pin1 mutants. The loss of function of PIN1 protein severely affects the formation of plant organs. Thus, the phenotype of an adult pin1 plant is characterized by the presence of leaves with altered morphology that lack serrations and a bare inflorescence stem that does not produce flowers or, if it does, they are sterile. This line was crossed with the cue1 mutant to obtain a pin1cue1 homozygous double mutant that gave rise to additive phenotypes with the appearance of 
the characteristic venosa phenotype and a bare inflorescence in adult plants (Figures $\mathbf{4 A}, \mathbf{B}$ ). Interestingly, the root length of the double pin1cue1 mutant is on average shorter than that of the parentals cue1 and pin1. These differences in average suggest that the inhibition of root growth associated with cue 1 entails the existence of additional mechanisms to the possible pin1 loss-of-function (Supplementary Figure 2A).

The expression of synthetic auxin response reporter construct DR5:GFP was decreased in the root of the cuel mutant, confirming that $\mathrm{NO}$ accumulation also inhibits auxin signaling in the root apical meristem (RAM; Fernández-Marcos et al., 2011). In order to establish the extent of its auxin signaling impairment and relation to the functionality and perception of the hormone, we introduced the cuel mutation into the loss-of-function axr1 (axr1-3) line (Lincoln et al., 1990) and studied the phenotype of the axrlcuel. The resulting double mutant mimicked to some extent, the adult plant phenotype displayed by the axr6 mutant (axr6-3; Quint et al., 2005; Figures $4 \mathrm{C}, \mathrm{D}$ ).

AUXIN RESISTANT 1 encodes a RUB-conjugating enzyme which regulates auxin Skp1/Cullin/F-box (SCF) activity (del Pozo et al., 1998), while AXR6 encodes the CUL1 subunit of the SCF complex (Hellmann et al., 2003). Loss-of-function axr1 and axr6 plants exhibited growth defects, including a slight reduction in plant height and an increased number of lateral branches. The adult phenotype of axr1-3 is significantly less severe than that of axr6-3 (Lincoln et al., 1990; Quint et al., 2005). Seven-week-old axr1cue1 plants display reduced stature, an increased number of branches compared to axr1 plants, and epinastic rosette leaves, similar to axr6 plants (Figure 4C). These phenotypes suggest that introducing cue1 in axr1 increases its resistance to auxin. Contrary to the phenotype exhibited in the above-ground organs, examination of the primary root length of 7-day-old axr1cue1 $(1.34 \pm 0.22 \mathrm{~cm}), \operatorname{axr} 1(1.68 \pm 0.28 \mathrm{~cm})$, cuel $(1.20 \pm 0.17 \mathrm{~cm})$, and wild type seedlings $(1.54 \pm 0.24 \mathrm{~cm})$ revealed that introducing the axrl mutation into the cuel background had no effect $(p>0.05)$ in root growth inhibition (Supplementary Figure 2B), highlighting specific NO effects depending on plant tissue.

\section{NO Disturbs the Accumulation of Auxin Maxima}

Reported evidences support that NO modulates root architecture by the control of auxin spatial pattern (Fernández-Marcos et al., 2011), but it remains unclear whether the crosstalk with NO could determine leaf phenotype. Leaf development is influenced by spatial patterns of auxin response based on auxin gradients (Avsian-Kretchmer et al., 2002; Heisler et al., 2005; Cheng et al., 2007). Using the auxin output reporter DR5:GUS (Ulmasov et al., 1997) for canonical auxin signaling, response-auxin sites were visualized in the leaf elongation tips during primordium development, that progressively moved to the margins by basipetal transport, hydathodes, trichomes, and mesophyll cells (Aloni et al., 2003).

We observed the expression pattern of DR5:GUS under wild type and different NO mutant backgrounds (Figure 5, Supplementary Figure 3) and subjected to NO treatments

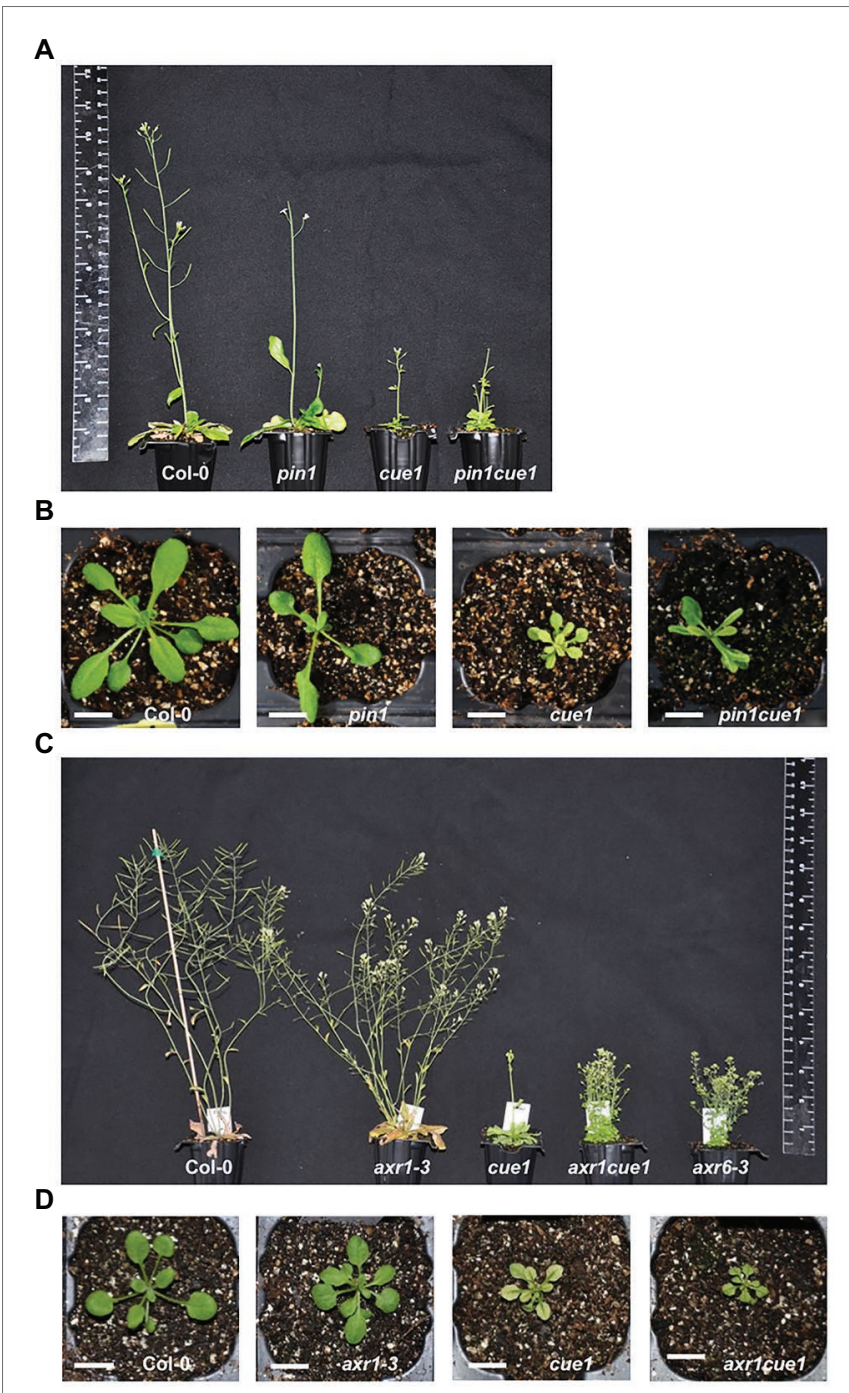

FIGURE 4 | The cue1 mutation alters auxin transport and increases auxin response impairment. Phenotype of 30-day-old plant rosettes $(\mathbf{A})$ and 21-day-old plant rosettes (B) in wild type (Col-0), pin1 mutant altered in auxin transport, NO overproducer cue1 mutant, and pin1cue1 double mutant. Phenotype of 50-day-old plant rosettes (C) and 21-day-old plant rosettes (D) in wild type (Col-0), axr6-3, axr1-3, cue1, and double axr1-3cue1. Plants were grown on $\mathrm{MS}$ for 14 days at $20^{\circ} \mathrm{C}$, then transferred to soil and grown in the greenhouse.

(Supplementary Figure 4), in order to analyze the effect of $\mathrm{NO}$ in the auxin maxima distribution.

In this context, $\mathrm{NO}$ overproducer mutants (Figure 5A, Supplementary Figure 3) and exogenous NO treatments (Supplementary Figure 4) decreased the expression of the auxin response reporter DR5:GUS, in contrast to the NO deficient noal-1 (Figure 5, Supplementary Figure 3) and NO scavenging (Supplementary Figure 4), which enhanced the detection of auxin maxima. Additionally, the pattern of auxin maxima in cue1/nox1 mutant was restored after $48 \mathrm{~h}$ of NO scavenger treatment (Supplementary Figure 4). These results were consistently observed during different developmental stages of leaf primordium (i.e., from the first 
and second leaves to the sixth true leaf stage), avoiding the highly pleiotropic phenotypes of NO homeostasis mutants compromise synchronization of growth to compare to the wild type.

In order to test the contribution of the two main pathways involved in NO production into the regulation of the pattern of auxin maxima, we used the available genetic tools for NIA1, NIA2, and NOA1. The most significant changes in the DR5:GUS expression pattern compared to the wild type were observed in the noa1-1 deficient mutant (Figure 5B), while nia1nia2 expression pattern was close to the wild type. These results suggest that NOA1 could have a main role in $\mathrm{NO}$ production during the regulation of auxin maxima distribution in shoots.

\section{NO Promotes PIN-FORMED1 Accumulation in Aerial Parts}

Auxin responses are based on dynamic spatial patterns mediated by the efflux transporter proteins, PIN-FORMED family, whose asymmetric localization promotes changes in polar auxin movements, leading to the correct hormone distribution (Palme and Gälweiler, 1999; reviewed in Friml, 2003). Within this family, PIN1 polar localization presents a prominent role determining auxin distribution in the aerial part (Benková et al., 2003). Previously, Fernández-Marcos et al. (2011) showed a PIN1 decrease in primary roots under NO treatments and in the cuel/nox 1 NO overproducer mutant. Additionally, the root meristem size of this mutant resembles that of the pin1 knock-out mutant phenotype

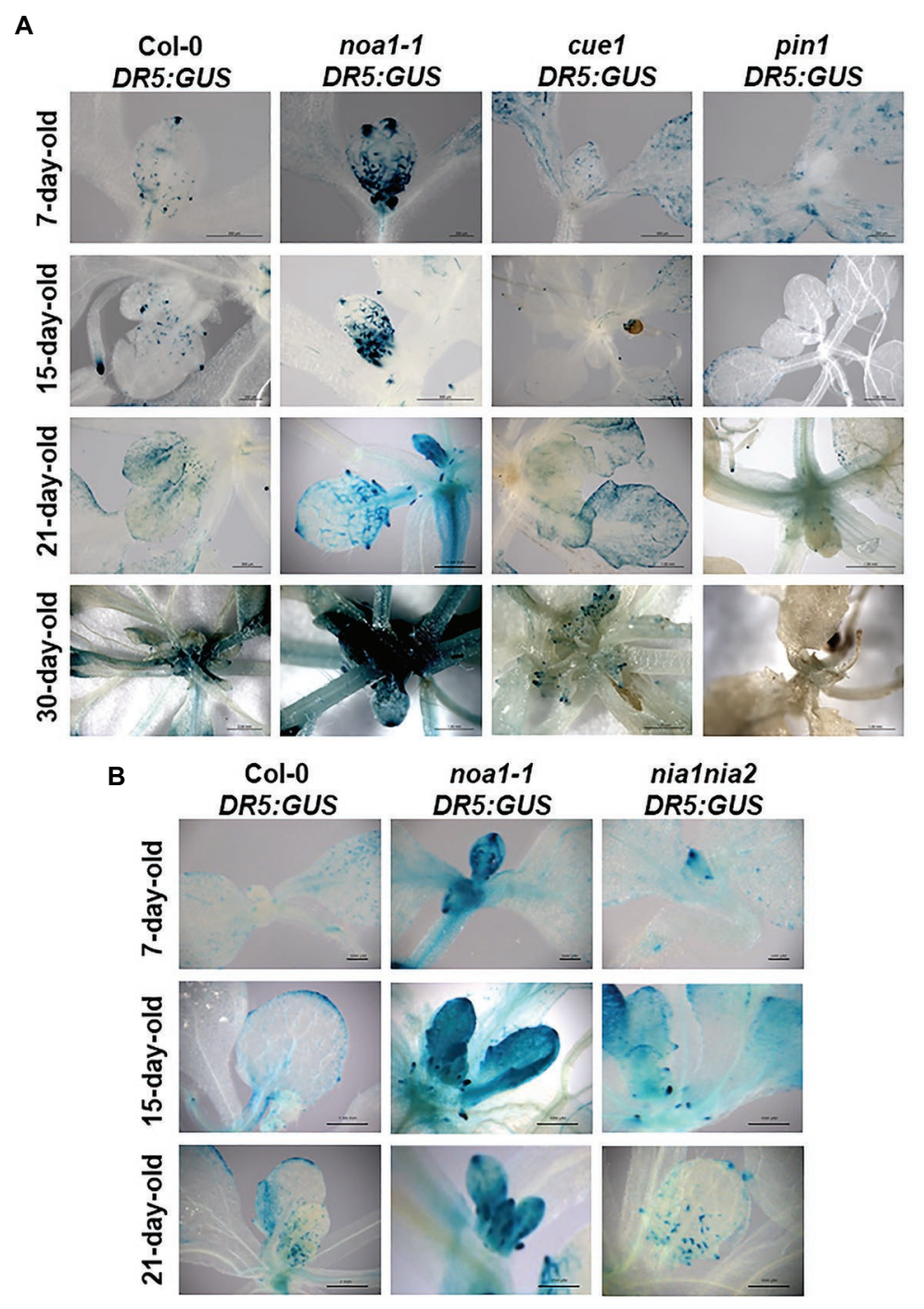

FIGURE 5 | Auxin response is impacted by mutations in NOA1 and CUE1. Pattern of DR5:GUS expression in transformed A. thaliana Col-0 and noa1-1, Cue1-1, and pin 1 mutant lines, showing histochemical localization of B-GUS activity during morphogenesis in first and second leaves of 7-day-old seedlings, sixth and seventh leaves of 15-day-old seedlings, leaves of 21-day-old plants, and 30-day-old plants (A). Scale bars, between 200 and 1,000 $\mu$ m. Histochemical localization was also showed in nia1nia2 NO deficient mutant in 7-, 15-, and 21-day-old plants (B). At least, 10 seedlings and plants per genotype were analyzed all showing a similar expression pattern and a representative image was selected. 
(Fernández-Marcos et al., 2011). To determine whether NO can affect PIN1 accumulation pattern during leaf development, we analyzed PIN1 protein levels in Arabidopsis young and rosettes leaves in different NO homeostasis mutant backgrounds (Figure 6).

Interestingly, we found a higher PIN1 accumulation in cue1/ nox 1 mutant compared to the wild type Col-0, along the different developmental stages of the aerial part analyzed (i.e., 7-, 10-, 15-, and 21-day-old seedlings grown in vitro and 21and 30-day-old plant rosettes grown on soil; Figure 6). Oppositely, a decrease of PIN1 accumulation is observed in all the NO deficient mutants analyzed (noa1, nia1nia2, and nia1nia2noa1-2; Figures 6A,B,D), except in 30-day-old noa1-1 plant rosettes grown on soil.

To better understand the role of NO in PIN1 localization and distribution during early development of leaves, we carried out a confocal analysis showing the distribution of PIN1-GFP protein in young leaves of seedlings grown in vitro and expressing the pPIN1:PIN1-GFP reporter gene under control of the PIN1 promoter (Figure 7). The different NO homeostasis mutant backgrounds analyzed included the NO overproducer cue1/ nox1 and the NO deficient noa1-1 mutants.

Thus, the quantitative results obtained with PIN1 accumulation (Figure 6) are fully supported by the confocal analysis, where we observed a reduction in the PIN1-GFP fluorescence pattern along the venations and the leaf margins in the noa 1-1 mutant, in comparison to the wild type and cuel/nox 1 background (Figure 7). This pattern was conserved in noa1-1;pPIN1:PIN1-GFP seedlings at every developmental stage analyzed from the first or second leaf margin (Figure 7A), in sixth and seventh leaf margin (Figure 7B) and in eleventh rosette leaf margin (Figure 7C).

A

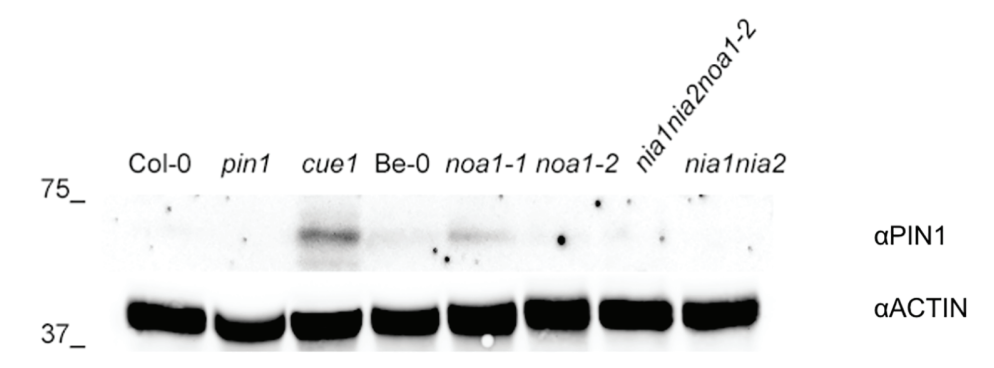

B

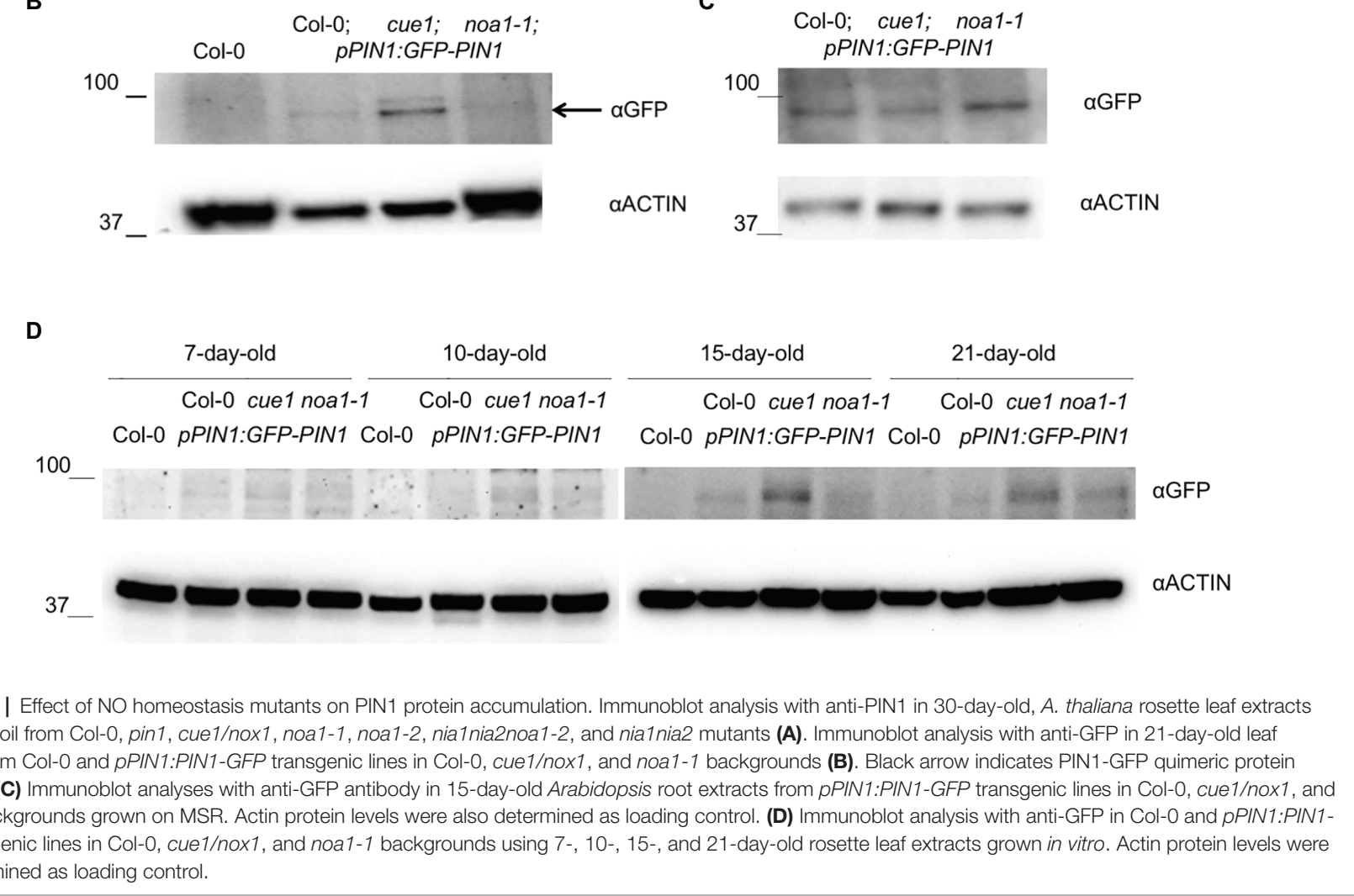

C Col-0; cue1; noa1-1 100 pPIN1:GFP-PIN1

FIGURE 6 | Effect of NO homeostasis mutants on PIN1 protein accumulation. Immunoblot analysis with anti-PIN1 in 30-day-old, $A$. thaliana rosette leaf extracts grown on soil from Col-0, pin1, cue1/nox1, noa1-1, noa1-2, nia1nia2noa1-2, and nia1nia2 mutants (A). Immunoblot analysis with anti-GFP in 21-day-old leaf extracts from Col-0 and pPIN1:PIN1-GFP transgenic lines in Col-0, cue1/nox1, and noa1-1 backgrounds (B). Black arrow indicates PIN1-GFP quimeric protein detection. (C) Immunoblot analyses with anti-GFP antibody in 15-day-old Arabidopsis root extracts from pPIN1:PIN1-GFP transgenic lines in Col-0, cue1/nox1, and noa1-1 backgrounds grown on MSR. Actin protein levels were also determined as loading control. (D) Immunoblot analysis with anti-GFP in Col-0 and pPIN1:PIN1GFP transgenic lines in Col-0, cue1/nox1, and noa1-1 backgrounds using 7-, 10-, 15-, and 21-day-old rosette leaf extracts grown in vitro. Actin protein levels were also determined as loading control. 
All together, these results suggest an opposite effect for NO during the regulation of PIN1 distribution in aerial parts compared to the previously reported in roots (Fernández-Marcos et al., 2011; Figure 6C). PIN1 trafficking is controlled in part by auxin (Paciorek et al., 2005), and free-auxin production shows a differential pattern in shoots compared to the root tips (Aloni et al., 2003). This is not surprising, because leaf and root primordia initiation and development are differentially regulated (Elliott et al., 1996; Malamy and Benfey, 1997).

\section{DISCUSSION}

Plants have evolved to adapt in a changing environment. Leaves exemplify this plasticity because of their highly variable morphology. Leaf organs play a key role in light capture and carbon fixing, modulating their structure depending on the external and internal cues. The complex network controlling leaf phenotype is composed by the interplay between hormones, transcription factors, and other components, such as secondary messengers or key gasotransmitters, like NO (Albertos et al., 2016) or oxygen. In roots, NO participates in many developmental cues (Pagnussat et al., 2003, 2004; Correa-Aragunde et al., 2006; Méndez-Bravo et al., 2010; Fernández-Marcos et al., 2011, 2012), but little is known about the regulation of leaf structure. Different NO homeostasis mutants present severe defects related to leaf phenotype, such as leaf number and margin, serrations, phyllotactic pattern, and number of siliques (Figures 2, 3, Supplementary Table 1). Based on our previous results that link NO effect to auxin transport and signaling inhibition in roots (Fernández-Marcos et al., 2011), we crossed the NO overproducer mutant cue1 with the loss-of-function mutants pin1 and axr1, in order to analyze the resulting phenotype (Figure 4). Double mutant pin1cue1 shows an additive phenotype (Figures 4A,B), while axrlcue1 resembles the partial auxin insensitivity displayed by axr6 (Quint et al., 2005) and shows defects, such as reduced stature, higher number of branches, and epinastic rosette leaves (Figures 4C,D). Root length of the double pin1cue1 mutant was shorter than the corresponding parentals (Supplementary Figure 2A), suggesting the existence

A
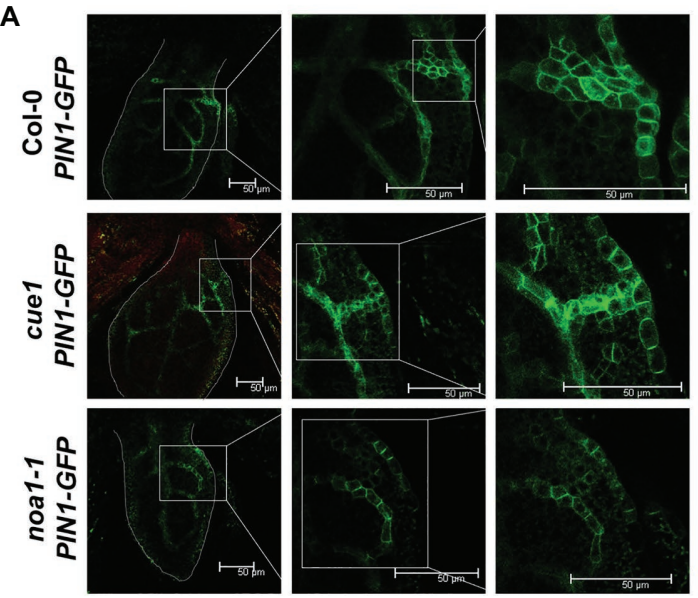

B
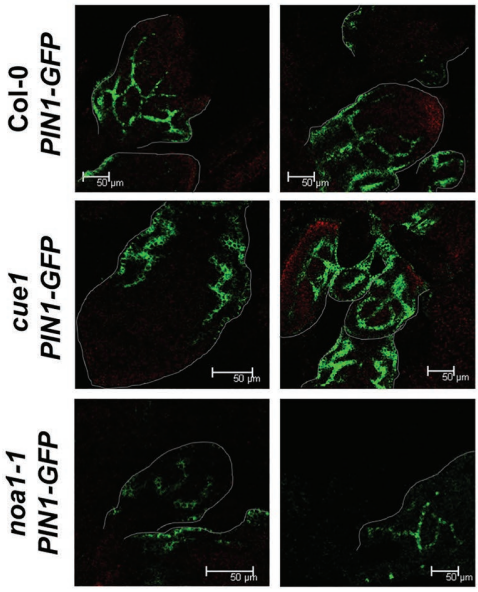

C
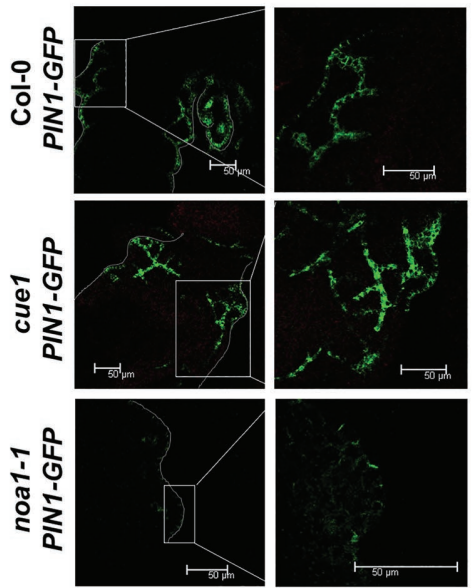

FIGURE 7 | Distribution of PIN1 in aerial parts of NO homeostasis mutants. Confocal micrographs showing the expression of pPIN1:PIN1-GFP in A. thaliana grown in vitro seedlings first or second leaf margin (A), in sixth and seventh leaf margin (B), and in eleventh rosette leaf margin (C). Col-0; $p P I N 1$ :PIN1-GFP, cue1; pPIN1:PIN1-GFP and noa1-1; and pPIN1:PIN1-GFP lines are shown. Scale bars, $50 \mu \mathrm{m}$. 
of additional mechanisms during the inhibition of root growth. Interestingly, no inhibition effect was observed during root growth of axr1cue1 (Supplementary Figure 2B), highlighting a great tissue specificity.

Expression of a NO degrading dioxygenase (NOD) has been described to initiate leaf senescence (Mishina et al., 2007). This result is in agreement with our observations of premature leaf senescence in 30-day-old plant of the NO deficient noa1-1 mutant (Guo et al., 2003; Figure 2). Additionally, a delay effect in leaf senescence induced by methyl jasmonate was observed when low salicylic acid concentrations are used, which depends on NOA1 pathway for NO production (Ji et al., 2016). Green reticulation on a paler lamina phenotype is a common feature between venosa and NO overaccumulator cuel/noxl mutants (Li et al., 1995). Nevertheless, the analysis of primary root length (Supplementary Figure 1) showed that not all the lines behave in a similar way to the NO donor application, suggesting that ven phenotype is independent of NO levels. The rescue of noal pale phenotype by $\mathrm{NO}$ exogenous treatment was previously described (Guo et al., 2003), but its specific role at this level remains unclear. This result highlights the complex network involved in leaf morphology and structure, where $\mathrm{NO}$ emerges as an important player.

Sites of NO synthesis have been described in primary leaves and trichomes (Tun et al., 2006; Corpas et al., 2009). Using the DAF-2DA fluorescence probe, we observed endogenous NO accumulation in younger seedling leaves, mainly in the SAM (Figure 1). As expected, the observed pattern was increased in the NO overaccumulator cue1/nox1 mutant background (Figure 1). Endogenous NO detection was also observed in the RAM (Fernández-Marcos et al., 2011; Sanz et al., 2014), suggesting a potential role for this molecule inside these specific tissues.

Auxin distribution regulates organ formation and sites of maxima accumulation point to the primordium initiation (Aloni et al., 2003; Benková et al., 2003). Using the auxin response reporter DR5:GUS (Ulmasov et al., 1997), we analyzed the NO effect in the sites of high free-auxin distribution of Arabidopsis seedling leaves. Auxin maxima were observed mainly in the leaf tip, that progressively moved to the margins, hydathodes, and basal sites (Figure 5), where venation formation occurs, as was previously described (Aloni et al., 2003; Mattsson et al., 2003). Lower NO levels increase auxin accumulation along the younger leaves and during whole plant development, finding the opposite effect under higher NO levels (Figure 5, Supplementary Figures 3, 4). To deep further into the source of NO production in this process, we detected the strongest ß-GUS activity in noa1-1 mutant, suggesting that NOA1 is the main enzymatic mechanism involved (Figure 5). Extensive crosstalk between NO and auxin has been reported at the level of synthesis, transport, perception (i.e., S-nitrosation of the auxin receptor protein TIR1), and signaling (i.e., degradation of Aux/IAAs and consequent activation of AUXIN RESPONSE FACTOR (ARF) genes; reviewed in Sanz et al., 2015).

Auxin spatial and temporal pattern involves polar transport mediated mainly by the PIN1 efflux carrier (Benková et al., 2003). In order to decipher the mechanisms by which $\mathrm{NO}$ modifies auxin maxima distribution, we checked PIN1 localization and accumulation in Arabidopsis leaf primordium and seedling leaves by confocal microscopy and western blot. Using the PPIN1:PIN1-GFP construction, we visualized PIN1 along the leaf margins and developing vasculature, as was previously localized (Benková et al., 2003; Reinhardt et al., 2003; Heisler et al., 2005; Hay et al., 2006). Interestingly, in cue1/nox1 mutant, we could detect an increase in PIN1 accumulation by western blot opposite to the effect of NO on PIN stability reported in roots (Figure 6), but the distribution pattern remains unchanged at the developmental stages analyzed (Figure 7). In contrast, noa1-1 mutant showed a dramatic decrease in PIN1-GFP fluorescence. Previous research showed that PIN1 activity promotes the formation of leaf serrations (Hay et al., 2006) and cue1/nox1 present leaf margins with more serrations compared to the Col-0 wild type (Figure 2), suggesting that NO could modify leaf morphology through PIN1 regulation. Furthermore, Fernández-Marcos et al. (2011) showed a decrease in PIN1 along the root meristem in the presence of NO, evidencing a differential effect of $\mathrm{NO}$ in the auxin maxima accumulation between shoots and roots. Supporting this result, Otvös et al. (2005) found that promotion of cell division mediated by auxin in cell derived from alfalfa leaf protoplasts, was increased in the presence of NO, whereas in roots, the opposite effect was observed (Fernández-Marcos et al., 2011).

PIN-FORMED 1 polar localization is regulated by several factors. Among them, stand out key proteins such as the transcriptional activator MONOPTEROS (MP), which belongs to the ARF family (Wenzel et al., 2007; Schuetz et al., 2008), GNOM ARF GEF affecting the endocytosis recycling (Steinmann et al., 1999; Geldner et al., 2003) and the protein kinase PINOID, that modulates PIN1 apical-basal location (Friml et al., 2004). Two feedback loops are described for PIN1 polar location and auxin maxima distribution along the leaf margins. The first links auxin transport to its own distribution through PIN1 localization. In the second loop, CUP-SHAPED COTYLEDON 2 (CUC2) controls PIN1 reorientation, being repressed by auxin at the same time (Bilsborough et al., 2011). To get further insights into the mechanisms by which NO could control PIN1 localization and the pattern of auxin maxima, we searched for in silico putative targets of $S$-nitrosation, in the main players involved in this process, by using the GPS-SNO 1.0 software (Xue et al., 2010). Interestingly, PINOID, CUC2, MP, and GNOM ARF GEF present Cys residues susceptible to suffer this post-translational modification (Table 1). Remarkably, MP and GNOM ARF GEF, with three and four SNO hypothetical modifications, respectively, suggest that NO can modulate auxin transport at different levels including transcriptional regulation and endocytosis recycling. Indeed, the PIN1 endocytic recycling cycle depends on the actin cytoskeleton (Geldner et al., 2001), whose structure is in part controlled by $S$-nitrosation (Lindermayr et al., 2005; Rodriguez-Serrano et al., 2014).

Together, these results provide new evidences on the regulation of NO during leaf morphology, as opposed to previous research on root development, and suggesting the 
TABLE 1 | Analysis of putative S-nitrosation modifications in Cys residues from the main proteins implicated in the regulation of PIN-FORMED 1 (PIN1) by using the GPS-SNO 1.0 software.

\begin{tabular}{llcc}
\hline PROTEIN & PROCESS & $\begin{array}{c}\text { TOTAL CYS } \\
\text { NUMBER }\end{array}$ & $\begin{array}{c}\text { PUTATIVE } \\
\text { SNO CYS }\end{array}$ \\
\hline PINOID & Apical-basal localization & 5 & 1 \\
ARF GEF & Endocytosis recycling & 32 & 4 \\
GNOM & Transcriptional activator & 19 & 3 \\
$\begin{array}{l}\text { MONOPTEROS } \\
\text { CUP SHAPED }\end{array}$ & $\begin{array}{l}\text { Reorientation in response } \\
\text { COTYLDON 2 }\end{array}$ & 6 & 1 \\
\hline
\end{tabular}

tissue specificity for NO function. NO homeostasis mutants are impaired in different parameters related to aerial part, highlighting leaf shape, serrations, and premature senescence. Auxin maxima decrease can be linked to PIN1 greater accumulation, as a compensatory mechanism, in order to maintain the auxin spatial pattern along leaf margins and venations. Leaf development is tightly modulated by external and internal cues, coupling shape with functionality to maximize plant adaptation to the environmental changes. Results presented in this work suggest an extensive crosstalk between different signals (i.e., auxin and NO) and provide putative NO targets to elucidate the complete network during shoot development.

\section{DATA AVAILABILITY STATEMENT}

The original contributions presented in the study are included in the article/Supplementary Material; further inquiries can be directed to the corresponding author.

\section{REFERENCES}

Adamakis, I.-D. S., Panteris, E., and Eleftheriou, E. P. (2014). Tungsten disrupts root growth in Arabidopsis thaliana by PIN targeting. J. Plant Physiol. 171, 1174-1187. doi: 10.1016/j.jplph.2014.04.010

Albertos, P., Sanz, L., Mateos, I., Sánchez-Vicente, I., Lechón, T., Fernández-Espinosa, G., et al. (2016). Gasotransmission of Nitric Oxide (NO) at Early Plant Developmental Stages. eds. L. Lamattina and C. García-Mata (Switzerland: Springer International Publishing).

Aloni, R., Schwalm, K., Langhans, M., and Ullrich, C. I. (2003). Gradual shifts in sites of free-auxin production during leaf-primordium development and their role in vascular differentiation and leaf morphogenesis in Arabidopis. Planta 216, 841-853. doi: 10.1007/s00425-002-0937-8

Astier, J., Gross, I., and Durner, J. (2018). Nitric oxide production in plants: an update. J. Exp. Bot. 69, 3401-3411. doi: 10.1093/jxb/erx420

Avsian-Kretchmer, O., Cheng, J. C., Chen, L., Moctezuma, E., and Sung, Z. R. (2002). Indole acetic acid distribution coincides with vascular differentiation pattern during Arabidopsis leaf ontogeny. Plant Physiol. 130, 199-209. doi: $10.1104 /$ pp.003228

Bai, S., Yao, T., Li, M., Guo, X., Zhang, Y., Zhu, S., et al. (2014). PIF3 is involved in the primary root growth inhibition of arabidopsis induced by nitric oxide in the light. Mol. Plant 7, 616-625. doi: 10.1093/ $\mathrm{mp} / \mathrm{sst} 142$

Benková, E., Michniewicz, M., Sauer, M., Teichmann, T., Seifertová, D., Jürgens, G., et al. (2003). Local, efflux-dependent auxin gradients as a common module for plant organ formation. Cell 115, 591-602. doi: 10.1016/S0092-8674 (03)00924-3

\section{AUTHOR CONTRIBUTIONS}

IS-V and TL performed research. MF-M and LS generated transgenic lines and performed root growth assays. IS- $\mathrm{V}$ and OL analyzed data and wrote the paper. OL conceived and designed research and supervised the work. All authors discussed the results and commented on the manuscript. All authors contributed to the article and approved the submitted version.

\section{FUNDING}

This work was financed by grants Fundación Solórzano (FS/16 2019) from the University of Salamanca (to IS-V), BIO201785758-R from the Ministerio de Ciencia, Innovación y Universidades (Spain), and SA313P18 and SA137P20 from Junta de Castilla y León and Escalera de Excelencia CLU-2018-04 co-funded by the P.O. FEDER of Castilla y León 2014-2020 Spain (to OL).

\section{ACKNOWLEDGMENTS}

We thank the Spanish networks BIO2015-68957-REDT and RED2018-102397-T for stimulating discussions, Teva Vernoux and Géraldine Brunoud their help with the phyllotactic pattern, and Rosa $\mathrm{M}^{\mathrm{a}}$ Ponce and José Luis Micol their advice on venosa mutants.

\section{SUPPLEMENTARY MATERIAL}

The Supplementary Material for this article can be found online at: https://www.frontiersin.org/articles/10.3389/fpls.2021.630792/ full\#supplementary-material

Berná, G., Robles, P., and Micol, J. L. (1999). A mutational analysis of leaf morphogenesis in Arabidopsis thaliana. Genetics 152, 729-742.

Besnard, F., Refahi, Y., Morin, V., Marteaux, B., Brunoud, G., Chambrier, P., et al. (2014). Cytokinin signalling inhibitory fields provide robustness to phyllotaxis. Nature 505, 417-421. doi: 10.1038/nature12791

Bilsborough, G. D., Runions, A., Bakoulas, M., Jenkins, H. W., Hasson, A., Galinha, C., et al. (2011). Model for the regulation of Arabidopsis thaliana leaf margin development. Proc. Natl. Acad. Sci. U. S. A. 108, 3424-3429. doi: 10.1073/pnas.1015162108

Bradford, M. (1976). A rapid and sensitive method for the quantitation of microgram quantities of protein utilizing the principle of protein-dye binding. Anal. Biochem. 72, 248-254. doi: 10.1016/0003-2697(76)90527-3

Cao, Z., Duan, X., Yao, P., Cui, W., Cheng, D., Zhang, J., et al. (2017). Hydrogen gas is involved in auxin-induced lateral root formation by modulating nitric oxide synthesis. Int. J. Mol. Sci. 18:2084. doi: 10.3390/ijms18102084

Chen, W. W., Yang, J. L., Qin, C., Jin, C. W., Mo, J. H., Ye, T., et al. (2010). Nitric oxide acts downstream of auxin to trigger root ferric-chelate reductase activity in response to iron deficiency in Arabidopsis. Plant Physiol. 154, 810-819. doi: 10.1104/pp.110.161109

Chen, J., Zhang, H.-Q., Hu, L.-B., and Shi, Z.-Q. (2013). Microcystin-LR-induced phytotoxicity in rice crown root is associated with the cross-talk between auxin and nitric oxide. Chemosphere 93, 283-293. doi: 10.1016/j.chemosphere.2013.04.079

Cheng, Y., Dai, X., and Zhao, Y. (2007). Auxin synthesized by the TUCCA flavin monooxygenases is essential for embryogenesis and leaf formation in Arabidopsis. Plant Cell 19, 2430-2439. doi: 10.1105/tpc.107.053009

Corpas, F. J., Hayashi, M., Mano, S., Nishimura, M., and Barroso, J. B. (2009). Peroxisomes are required for in vivo nitric oxide accumulation in the cytosol 
following salinity stress of Arabidopsis plants. Plant Physiol. 151, 2083-2094. doi: $10.1104 /$ pp.109.146100

Correa-Aragunde, N., Graziano, M., Chevalier, C., and Lamattina, L. (2006). Nitric oxide modulates the expression of cell cycle regulatory genes during lateral root formation in tomato. J. Exp. Bot. 57, 581-588. doi: 10.1093/jxb/ erj045

del Pozo, J. C., Timpte, C., Tan, S., Callis, J., and Estelle, M. (1998). The ubiquitin related protein RUB1 and auxin response in Arabidopsis. Science 280, 1760-1763. doi: 10.1126/science.280.5370.1760

Elhiti, M., Hebelstrup, K. H., Wang, A., Li, C., Cui, Y., Hill, R. D., et al. (2013). Function of type-2 Arabidopsis hemoglobin in the auxin-mediated formation of embryogenic cells during morphogenesis. Plant J. 74, 946-958. doi: $10.1111 /$ tpj.12181

Elliott, R. C., Betzner, A. S., Huttner, E., Oakes, M. P., Tucker, W. Q., Gerentes, D., et al. (1996). AINTEGUMENTA, an APETALA2-like gene of Arabidopsis with pleiotropic roles in ovule development and floral organ growth. Plant Cell 8, 155-168. doi: 10.1105/tpc.8.2.155

Fattorini, L., Veloccia, A., Della Rovere, F., D’Angeli, S., Falasca, G., and Altamura, M. M. (2017). Indole-3-butyric acid promotes adventitious rooting in Arabidopsis thaliana thin cell layers by conversion into indole-3-acetic acid and stimulation of anthranilate synthase activity. BMC Plant Biol. 17:121. doi: 10.1186/s12870-017-1071-x

Fernández-Marcos, M., Sanz, L., Lewis, D. R., Muday, G. K., and Lorenzo, O. (2011). Nitric oxide causes root apical meristem defects and growth inhibition while reducing PIN-FORMED 1 (PIN1)-dependent acropetal auxin transport. Proc. Natl. Acad. Sci. U. S. A. 108, 18506-18511. doi: 10.1073/pnas.1108644108

Fernández-Marcos, M., Sanz, L., and Lorenzo, O. (2012). Nitric oxide: an emerging regulator of cell elongation during primary root growth. Plant Signal. Behav. 7, 196-200. doi: 10.4161/psb.18895

Flores, T., Todd, C. D., Tovar-Mendez, A., Dhanoa, P. K., Correa-Aragunde, N., Hoyos, M. E., et al. (2008). Arginase-negative mutants of Arabidopsis exhibit increased nitric oxide signaling in root development. Plant Physiol. 147, 1936-1946. doi: 10.1104/pp.108.121459

Freschi, L. (2013). Nitric oxide and phytohormone interactions: current status and perspectives. Front. Plant Sci. 4:398. doi: 10.3389/fpls.2013.00398

Friml, J. (2003). Auxin transport-shaping the plant. Curr. Opin. Plant Biol. 6, 7-12. doi: 10.1016/S1369526602000031

Friml, J., Yang, X., Michniewicz, M., Weiiers, D., Quint, A., Tietz, O., et al. (2004). A PINOID-dependent binary switch in apical-basal PIN polar targeting directs auxin efflux. Science 306, 862-865. doi: 10.1126/science.1100618

Galvan-Ampudia, C. S., Chaumeret, A. M., Godin, C., and Vernoux, T. (2016). Phyllotaxis: from patterns of organogenesis at the meristem to shoot architecture. Wiley Interdiscip. Rev. Dev. Biol. 5, 460-473. doi: 10.1002/wdev.231

Geldner, N., Anders, N., Wolters, H., Keicher, J., Kornberger, W., Muller, P., et al. (2003). The Arabidopsis GNOM ARF-GEF mediates endosomal recycling, auxin transport, and auxin-mediated plant growth. Cell 112, 219-230. doi: 10.1016/S0092-8674(03)00003-5

Geldner, N., Friml, J., Stierhof, Y. D., Jürgens, G., and Palme, K. (2001). Auxin transport inhibitors block PIN1 cycling and vesicle trafficking. Nature 413, 425-428. doi: 10.1038/35096571

González-Bayón, R., Kinsman, E. A., Quesada, V., Vera, A., Robles, P., Ponce, M. R., et al. (2006). Mutations in the RETICULATA gene dramatically alter internal architecture but have little effect on overall organ shape in Arabidopsis leaves. J. Exp. Bot. 57, 3019-3031. doi: 10.1093/jxb/erl063

Guo, F. Q., Okamoto, M., and Crawford, N. M. (2003). Identification of a plant nitric oxide synthase gene involvec in hormonal signaling. Science 302, 100-103. doi: 10.1126/science. 1086770

Hay, A., Barkoulas, M., and Tsiantis, M. (2006). ASYMMETRIC LEAVES1 and auxin activities converge to repress BREVIPEDICELLUS leaf development in Arabidopsis. Development 133, 3955-3961. doi: 10.1242/dev.02545

He, Y., He, Y., Tang, R., Hao, Y., Stevens, R., Cook, C., et al. (2004). Nitric oxide represses the Arabidopsis floral transition. Science 305, 1968-1971. doi: 10.1126/science.1098837

Heisler, M. G., Ohno, C., Das, P., Sieber, P., Reddy, G. V., Long, J. A., et al. (2005). Patterns of auxin transport and gene expression during primordium development revealed by live imaging of the Arabidopsis inflorescence meristem. Curr. Biol. 15, 1899-1911. doi: 10.1016/j.cub.2005.09.052

Hellmann, H., Hobbie, L., Chapman, A., Dharmasiri, S., Dharmasiri, N., del Pozo, C., et al. (2003). Arabidopsis AXR6 encodes CUL1 implicating SCF
E3 ligases in auxin regulation of embryogenesis. EMBO J. 22, 3314-3325. doi: $10.1093 / \mathrm{emboj} / \mathrm{cdg} 335$

Ji, Y., Liu, J., and Xing, D. (2016). Low concentrations of salicylic acid delay methyl jasmonate-induced leaf senescence by up-regulating nitric oxide synthase activity. J. Exp. Bot. 67, 5233-5245. doi: 10.1093/jxb/erw280

Kinsman, E. A., and Pyke, K. A. (1998). Bundle sheath cells and cell-specific plastid development in Arabidopsis leaves. Development 125, 1815-1822.

Kolbert, Z., Bartha, B., and Erdei, L. (2008). Exogenous auxin-induced NO synthesis is nitrate reductase-associated in Arabidopsis thaliana root primordia. J. Plant Physiol. 165, 967-975. doi: 10.1016/j.jplph.2007.07.019

Kolbert, Z., and Erdei, L. (2008). Involvement of nitrate reductase in auxininduced NO synthesis. Plant Signal. Behav. 11, 972-973. doi: 10.4161/psb.6170

Lechón, T., Sanz, L., Sánchez-Vicente, I., and Lorenzo, O. (2020). Nitric oxide overproduction by cue1 mutants differs on developmental stages and growth conditions. Plants 9:1484. doi: 10.3390/plants9111484

Li, H., Culligan, K., Dixon, R. A., and Chory, J. (1995). CUE1: a mesophyll cell-specific positive regulator of light-controlled gene expression in Arabidopsis. Plant Cell 7, 1599-1610. doi: 10.2307/3870022

Lincoln, C., Britton, J. H., and Estelle, M. (1990). Growth and development of the axr1 mutants of Arabidopsis. Plant Cell 2, 1071-1080. doi: 10.1105/ tpc.2.11.1071

Lindermayr, C., Saalbach, G., and Durner, J. (2005). Proteomic identification of S-nitrosylated proteins in arabidopsis. Plant Physiol. 137, 921-930. doi: 10.1104/pp.104.058719

Liu, F., and Guo, F. Q. (2013). Nitric oxide deficiency accelerates chlorophyll breakdown and stability loss of thylakoid membranes during dark-induced leaf senescence in Arabidopsis. PLoS One 8:e56345. doi: 10.1371/journal.pone.0056345

Liu, M., Zhang, H., Fang, X., Zhang, Y., and Jin, C. (2018). Auxin acts downstream of ethylene and nitric oxide to regulate magnesium deficiency-induced root hair development in Arabidopsis thaliana. Plant Cell Physiol. 59, 1452-1465. doi: $10.1093 / \mathrm{pcp} / \mathrm{pcy} 078$

Lombardo, M. C., Graziano, M., Polacco, J. C., and Lamattina, L. (2006). Nitric oxide functions as a positive regulator of root hair development. Plant Signal. Behav. 1, 28-33. doi: 10.4161/psb.1.1.2398

Lv, S. F., Jia, M. Z., Zhang, S. S., Han, S., and Jiang, J. (2019). The dependence of leaf senescence on the balance between 1-aminocyclopropane-1-carboxylate acid synthase 1 (ACS1)-catalysed ACC generation and nitric oxide-associated 1 (NOS1)-dependent NO accumulation in Arabidopsis. Plant Biol. 21, 595-603. doi: 10.1111/plb.12970

Malamy, J. E., and Benfey, P. N. (1997). Organization and cell differentiation in lateral roots of Arabidopsis thaliana. Development 124, 33-44.

Manoli, A., Trevisan, S., Voigt, B., Yokawa, K., Baluška, F., and Quaggiotti, S. (2015). Nitric oxide-mediated maize root apex responses to nitrate are regulated by Auxin and Strigolactones. Front. Plant Sci. 6:1269. doi: 10.3389/fpls.2015.01269

Marcos, D., and Berleth, T. (2014). Dynamic auxin transport patterns proceding vein formation revealed by live-imaging of Arabidopsis leaf primordia. Front. Plant Sci. 5:235. doi: 10.3389/fpls.2014.00235

Mattsson, J., Ckurshumova, W., and Berleth, T. (2003). Auxin signaling in Arabidopsis leaf vascular development. Plant Physiol. 131, 1327-1339. doi: 10.1104/pp.013623

Méndez-Bravo, A., Raya-González, J., Herrera-Estrella, L., and López-Bucio, J. (2010). Nitric oxide is involved in alkamide-induced lateral root development in Arabidopsis. Plant Cell Physiol. 51, 1612-1626. doi: 10.1093/pcp/pcq117

Mishina, T. E., Lamb, C., and Zeier, J. (2007). Expresison of a nitric oxide degrading enzyme induces a senescence programme in arabidopsis. Plant Cell Environ. 30, 39-52. doi: 10.1111/j.1365-3040.2006.01604.x

Moro, C. F., Gaspar, M., da Silva, F. R., Pattathil, S., Hahn, M. G., Salgado, I., et al. (2017). S-nitrosoglutathione promotes cell wall remodelling, alters the transcriptional profile and induces root hair formation in the hairless root hair defective 6 (rhd6) mutant of Arabidopsis thaliana. New Phytol. 213, 1771-1786. doi: 10.1111/nph.14309

Murashige, T., and Skoog, F. (1962). A revised medium for rapid growth and bioassays with tobacco tissue culture. Physiol. Plant. 15, 473-497. doi: 10.1111/j.1399-3054.1962.tb08052.x

Ni, M., Zhang, L., Shi, Y.-F., Wang, C., Lu, Y., Pan, J., et al. (2017). Excessive cellular S-nitrosothiol impairs endocytosis of Auxin efflux transporter PIN2. Front. Plant Sci. 8:1988. doi: 10.3389/fpls.2017.01988

Otvös, K., Pasternak, T. P., Miskolczi, P., Domoki, M., Dorigotov, D., Szucs, A., et al. (2005). Nitric oxide is required for, and promotes auxin-mediated 
activation of, cell division and embryogenic cell formation but does not influence cell cycle progression in alfalfa cell cultures. Plant J. 43, 849-860. doi: 10.1111/j.1365-313X.2005.02494.x

Paciorek, T., Zazímalová, E., Ruthard, N., Petrásek, J., Stierhof, Y. D., Kleine-Vehn, J., et al. (2005). Auxin inhibits endocytosis and promotes its own efflux from cells. Nature 435, 1251-1256. doi: 10.1038/nature03633

Pagnussat, G. C., Lanteri, M. L., and Lamattina, L. (2003). Nitric oxide and cyclic GMP are messengers in the indole acetic acid-induces adventitius rooting process. Plant Physiol. 132, 1241-1248. doi: 10.1104/pp.103.022228

Pagnussat, G. C., Lanteri, M. L., Lombardo, M. C., and Lamattina, L. (2004). Nitric oxide mediates the indole acetic acid induction activation of a mitogenactivated protein kinase cascade involved in adventitious root development. Plant Physiol. 135, 279-286. doi: 10.1104/pp.103.038554

Palme, K., and Gälweiler, L. (1999). PIN-pointing the molecular basis of auxin transport. Curr. Opin. Plant Biol. 2, 375-381. doi: 10.1016/S1369-5266(99)00008-4

París, R., Vazquez, M. M., Graziano, M., Terrile, M. C., Miller, N. D., Spalding, E. P., et al. (2018). Distribution of endogenous NO regulates early gravitropic response and PIN2 localization in Arabidopsis roots. Front. Plant Sci. 9:495. doi: 10.3389/fpls.2018.00495

Peaucelle, A., Morin, H., Traas, J., and Laufs, P. (2007). Plants expressing a miR164-resistant CUC2 gene reveal the importance of post-meristematic maintenance of phyllotaxy in Arabidopsis. Development 134, 1045-1050. doi: $10.1242 /$ dev. 02774

Pérez-Pérez, J. M., Esteve-Bruna, D., González-Bayón, R., Kangasjärvi, S., Caldana, C., Hannah, M. A., et al. (2013). Functional redundancy and divergence within the arabidopsis RETICULATA-RELATED gene family. Plant Physiol. 162, 589-603. doi: 10.1104/pp.113.217323

Pető, A., Lehotai, N., Lozano-Juste, J., León, J., Tari, I., Erdei, L., et al. (2011). Involvement of nitric oxide and auxin in signal transduction of copper induced morphological responses in Arabidopsis seedlings. Ann. Bot. 108, 449-457. doi: 10.1093/aob/mcr176

Qi, J., Wang, Y., Yu, T., Cunha, A., Wu, B., Vernoux, T., et al. (2014). Auxin depletion from leaf primordia contributes to organ patterning. Proc. Natl. Acad. Sci. U. S. A. 11, 18769-18774. doi: 10.1073/pnas.1421878112

Quint, M., Ito, H., Zhang, W., and Gray, W. M. (2005). Characterization of a novel temperature-sensitive allele of the CUL1/AXR6 subunit of SCF ubiquitin ligases. Plant J. 43, 371-383. doi: 10.1111/j.1365-313X.2005.02449.x

Reinhardt, D., Mandel, T., and Kuhlemeier, C. (2000). Auxin regulates the initiation and radical position of plant lateral organs. Plant Cell 12, 507-518. doi: $10.1105 /$ tpc.12.4.507

Reinhardt, D., Pesce, E. R., Stieger, P., Mandel, T., Baltensperger, K., Bennett, M., et al. (2003). Regulation of phyllotaxis by polar auxin transport. Nature 426, 255-260. doi: 10.1038/nature02081

Robles, P., and Micol, J. L. (2001). Genome-wide linkage analysis of Arabidopsis genes required for leaf development. Mol. Gen. Genomics. 266, 12-19. doi: 10.1007/s004380100535

Rodriguez-Serrano, M., Pazmino, D. M., Sparkes, I., Rochetti, A., Hawes, C., Romero-Puertas, M. C., et al. (2014). 2,4-dichlorophenoxyacetic acid promotes S-nitrosylation and oxidation of actin affecting cytoskeleton and peroxisomal dynamics. J. Exp. Bot. 65, 4783-4793. doi: 10.1093/jxb/eru237

Rosar, C., Kanonenberg, K., Nanda, A. M., Mielewczik, M., Bräutigam, A., Novák, O., et al. (2012). The leaf reticulate mutant dovl is impaired in the first step of purine metabolism. Mol. Plant. 5, 1127-1241. doi: 10.1093/mp/ sss 045

Sanz, L., Albertos, P., Mateos, I., Sánchez-Vicente, I., Lechón, T., Fernández-Marcos, M., et al. (2015). Nitric oxide (NO) and phytohormones crosstalk during early plant development. J. Exp. Bot. 66, 2857-2868. doi: $10.1093 /$ jxb/erv213

Sanz, L., Fernández-Marcos, M., Modrego, A., Lewis, D. R., Muday, G. K., Pollmann, S., et al. (2014). Nitric oxide plays a role in stem cell niche homeostasis through its interaction with auxin. Plant Physiol. 166, 1972-1984. doi: $10.1104 / p p .114 .247445$

Schlicht, M., Ludwig-Müller, J., Burbach, C., Volkmann, D., and Baluska, F. (2013). Indole-3-butyric acid induces lateral root formation via peroxisomederived indole-3-acetic acid and nitric oxide. New Phytol. 200, 473-482. doi: $10.1111 /$ nph.12377

Schuetz, M., Berleth, T., and Mattsson, J. (2008). Multiple MONOPTEROSdependent pathways are involved in leaf initiation. Plant Physiol. 148, 870-880. doi: $10.1104 / p p \cdot 108.119396$
Shi, H., Liu, W., Wei, Y., and Ye, T. (2017). Integration of auxin/indole-3-acetic acid 17 and RGA-LIKE3 confers salt stress resistance through stabilization by nitric oxide in Arabidopsis. J. Exp. Bot. 68, 1239-1249. doi: 10.1093/jxb/erw508

Shi, Y.-F., Wang, D.-L., Wang, C., Culler, A. H. H., Kreiser, M. A. A., Suresh, J., et al. (2015). Loss of GSNOR1 function leads to compromised Auxin signaling and polar Auxin transport. Mol. Plant. 8, 1350-1365. doi: 10.1016/j. molp.2015.04.008

Steinmann, T., Geldner, N., Grebe, M., Mangold, S., Jackson, C. L., Paris, S., et al. (1999). Coordinated polar localization of auxin efflux carrier PIN1 by GNOM ARF GEF. Science 286, 316-318. doi: 10.1126/science.286.5438.316

Stöhr, C., and Stremlau, S. (2006). Formation and possible roles of nitric oxide in plant roots. J. Exp. Bot. 57, 463-470. doi: 10.1093/jxb/erj058

Sun, H., Feng, F., Liu, J., and Zhao, Q. (2017). The interaction between Auxin and nitric oxide regulates root growth in response to iron deficiency in rice. Front. Plant Sci. 8:2169. doi: 10.3389/fpls.2017.02169

Terrile, M. C., París, R., Calderón-Villalobos, L. I. A., Iglesias, M. J., Lamattina, L., Estelle, M., et al. (2012). Nitric oxide influences auxin signaling through $S$-nitrosylation of the Arabidopsis TRANSPORT INHIBITOR RESPONSE 1 auxin receptor. Plant J. 70, 492-500. doi: 10.1111/j.1365-313X.2011.04885.x

Tun, N. N., Santa-Catarina, C., Begum, T., Silveira, V., Handro, W., Floh, E. I. S., et al. (2006). Polyamines induce rapid biosynthesis of nitric oxide (NO) in Arabidopsis thaliana seedlings. Plant Cell Physiol. 47, 346-354. doi: 10.1093/ pcp/pci252

Ulmasov, T., Murfett, J., Hagen, G., and Guilfoyle, T. J. (1997). Aux/IAA proteins repress expression of reporter genes containing natural and highly active synthetic auxin response elements. Plant Cell 9, 1963-1971. doi: 10.1105/ tpc.9.11.1963

Vitor, S. C., Duarte, G. T., Saviani, E. E., Vincentz, M. G. A., Oliveira, H. C., and Salgado, I. (2013). Nitrate reductase is required for the transcriptional modulation and bactericidal activity of nitric oxide during the defense response of Arabidopsis thaliana against Pseudomonas syringae. Planta 238, 475-486. doi: 10.1007/s00425-013-1906-0

Wang, Y., Ries, A., Wu, K., Yang, A., and Crawford, N. M. (2010). The Arabidopsis prohibitin gene $P H B 3$ functions in nitric oxide-mediated responses and in hydrogen peroxide-induced nitric oxide accumulation. Plant Cell 22, 249-259. doi: $10.1105 /$ tpc. 109.072066

Ware, A., Walker, C. H., Šimura, J., González-Suárez, P., Ljung, K., Bishopp, A., et al. (2020). Auxin export from proximal fruits drives arrest in temporally competent inflorescences. Nat. Plants 6, 699-707. doi: 10.1038/s41477-020-0661-z

Wen, D., Gong, B., Sun, S., Liu, S., Wang, X., Wei, M., et al. (2016). Promoting roles of melatonin in adventitious root development of Solanum lycopersicum L. by regulating Auxin and nitric oxide signaling. Front. Plant Sci. 7:718. doi: $10.3389 /$ fpls.2016.00718

Wenzel, C. L., Schuetz, M., Yu, Q., and Mattsson, J. (2007). Dynamics of MONOPTEROS and PIN-FORMED1 expression during leaf vein pattern formation in Arabidopsis thaliana. Plant J. 49, 387-398. doi: 10.1111/ j.1365-313X.2006.02977.x

Xu, J., Wang, W., Yin, H., Liu, X., Sun, H., and Mi, Q. (2010). Exogenous nitric oxide improves antioxidative capacity and reduces auxin degradation in roots of Medicago truncatula seedlings under cadmium stress. Plant Soil 326, 321-330. doi: 10.1007/s11104-009-0011-4

Xue, Y., Liu, Z., Gao, X., Jin, C., Wen, L., Yao, X., et al. (2010). GPS-SNO: computational prediction of protein S-nitrosylation sites with a modified GPS algorithm. PLoS One 5:e11290. doi: 10.1371/journal.pone.0011290

Yuan, H.-M., and Huang, X. (2016). Inhibition of root meristem growth by cadmium involves nitric oxide-mediated repression of auxin accumulation and signalling in Arabidopsis. Plant Cell Environ. 39, 120-135. doi: 10.1111/ pce. 12597

Conflict of Interest: The authors declare that the research was conducted in the absence of any commercial or financial relationships that could be construed as a potential conflict of interest.

Copyright (๔) 2021 Sánchez-Vicente, Lechón, Fernández-Marcos, Sanz and Lorenzo. This is an open-access article distributed under the terms of the Creative Commons Attribution License (CC BY). The use, distribution or reproduction in other forums is permitted, provided the original author(s) and the copyright owner(s) are credited and that the original publication in this journal is cited, in accordance with accepted academic practice. No use, distribution or reproduction is permitted which does not comply with these terms. 